\title{
DEM investigation on dissociation characteristics of methane hydrate bearing sediments by chemical injection method
}

\author{
Mingjing Jiang ${ }^{\text {i) }}$, Ruohan Sun ${ }^{\text {ii) }}$ and Wenhao Du ${ }^{\text {iii) }}$ \\ i) Professor, Department of Civil Engineering, Tianjin University, No.135 Yaguan Road, Tianjin, China,300354; \\ Professor, College of Civil Engineering, Tongji University, No. 1239 Siping Road, Shanghai, China,200092. \\ ii) Ph. D Student, Department of Civil Engineering, Tianjin University, No.135 Yaguan Road, Tianjin, China,300354. \\ iii) Engineer, Tongji Architectural Design (Group) Co., Ltd., No. 1230 Siping Road, Shanghai, China,200092.
}

\begin{abstract}
Methane hydrate $(\mathrm{MH})$ is regarded as a potential future clean energy source, which has attracted lots of attention in recent decades. The sediment containing MH is called as Methane Hydrates Bearing Sediment (MHBS). The evolutions of mechanical behaviors of MHBS from macro and micro scales are needed in detail for safe $\mathrm{MH}$ exploitation (e.g., chemical injection method). For this purpose, a novel 3D thermo-hydro-mechanical-chemical (THMC) bond contact model was proposed and implemented into a DEM commercial software to capture the mechanical behavior of MHBS under exploitation stress path. Firstly, MHBS samples were compressed to different deviator stress levels, which represents the different initial stress state. Then the chemical injection process was simulated by increasing the salinity from $3 \mathrm{wt} \%$ to $14 \mathrm{wt} \%$ to allow $\mathrm{MH}$ dissociate while the deviator stress remained constant. After which, the recovery stage was simulated by decreasing the salinity from $14 \mathrm{wt} \%$ to $3 \mathrm{wt} \%$. The results show that the salinity can affect the mechanical behavior of MHBS by changing the properties of inter-particle methane hydrate. During chemical injection process, the axial strain increases with the increase of salinity. The chemical injection method will result in soil collapse when initial deviator stress is larger than the strength of pure sand at exploitation stage but slight deformation at recover stage.
\end{abstract}

Keywords: methane hydrate bearing sediments, thermo-hydro-mechanical-chemical contact model, chemical, discrete element method, macro and micro mechanical responses

\section{INTRODUCTION}

Methane hydrate $(\mathrm{MH})$ is a new source of clean energy, and the sediment containing $\mathrm{MH}$ is usually referred as the Methane Hydrate-Bearing sediments (MHBS) (Kvenvolden, 1988). Extracting methane gas from MHBS may cause destabilization of MHBS and lead to excessive settlement or submarine landslides of the seabed. Therefore, how to exploit MH safely and efficiently has become a worldwide focus (Englezos et al., 1993).

The production of $\mathrm{MH}$ is currently by using such methods as depressurization, thermal stimulation, and chemical injection (Moridis et al., 2004). Various laboratory tests have been performed on artificial MHBS samples to study their macro mechanical properties during thermal and depressurization methods (Masui et al., 2005; Hyodo et al., 2005; Hyodo et al., 2013; Yu et al., 2011), which provide lots of valuable conclusions in evaluating the changes of MHBS properties. However, laboratory tests are faced with challenges with regard to replicating samples with the same physical properties and visualizing the changes of microscopic structure, which is believed to underlie the macroscopic behaviors.

The discrete element method (DEM) (Cundall and Strack, 1979) has been recently employed in the research of MHBS. Jiang et al. (2016) analyzed the macro- and micro- mechanical behaviors of MHBS during exploitation by thermal recovery and depressurization methods with DEM. However, there is no experiments and numerical simulations analyzing the mechanical behavior of MHBS under different $\mathrm{NaCl}$ solutions, which constitutes the strong motivation of this study.

A proper bond contact model is required to capture the mechanical behavior of MHBS with DEM. The previous bond contact model proposed by Shen and Jiang (2016) ignores the effect of salinity on the contact behavior between MHBS particles. Thus, a new thermo-hydro-mechanical-chemical bond contact model was proposed in this paper based on the strength failure law from laboratory tests (Jiang et al., 2015), which was then implemented into PFC3D to simulate mechanical properties of MHBS subjected to chemical injection method. 


\section{NEW BOND CONTACT MODEL FOR MHBS}

This model regards the transmission of forces at contact as a combination of two parts: the particle contact part and the $\mathrm{MH}$ bond contact part, which can be estimated as follows:

$$
\begin{gathered}
\boldsymbol{F}_{\mathrm{n}}=\boldsymbol{F}_{\mathrm{n}}^{\mathrm{p}}+\boldsymbol{F}_{\mathrm{n}}^{\mathrm{b}} \\
\boldsymbol{F}_{\mathrm{s}}=\boldsymbol{F}_{\mathrm{s}}^{\mathrm{p}}+\boldsymbol{F}_{\mathrm{s}}^{\mathrm{b}} \\
\boldsymbol{M}_{\mathrm{r}}=\boldsymbol{M}_{\mathrm{r}}^{\mathrm{p}}+\boldsymbol{M}_{\mathrm{r}}^{\mathrm{b}} \\
\boldsymbol{M}_{\mathrm{t}}=\boldsymbol{M}_{\mathrm{t}}^{\mathrm{p}}+\boldsymbol{M}_{\mathrm{t}}^{\mathrm{b}}
\end{gathered}
$$

where $\boldsymbol{F}_{\mathrm{n}}, \boldsymbol{F}_{\mathrm{s}}, \boldsymbol{M}_{\mathrm{r}}$ and $\boldsymbol{M}_{\mathrm{t}}$ are the total normal force due to compression, shear force due to relative displacement, bending moment due to rolling angle and torque due to twisting angle at each contact, respectively; $\boldsymbol{F}_{\mathrm{n}}^{\mathrm{p}}, \boldsymbol{F}_{\mathrm{s}}^{\mathrm{p}}, \boldsymbol{M}_{\mathrm{r}}^{\mathrm{p}}$ and $\boldsymbol{M}_{\mathrm{t}}^{\mathrm{p}}$ denote the particle normal force, particle tangential force, particle rolling moment and particle torque, respectively. And $\boldsymbol{F}_{\mathrm{n}}^{\mathrm{b}}$, $\boldsymbol{F}_{\mathrm{s}}^{\mathrm{b}}, \boldsymbol{M}_{\mathrm{r}}^{\mathrm{b}}$ and $\boldsymbol{M}_{\mathrm{t}}^{\mathrm{b}}$ denote the normal force, shear force, bending moment and torque of $\mathrm{MH}$ bond contact respectively.

\subsection{Force-displacement relationship and strength criterion of the contact model}

For particle contact, the mechanical response could be described by following equations (Jiang et al., 2015a).

$$
\begin{gathered}
\boldsymbol{F}_{\mathrm{n}}^{\mathrm{p}}= \begin{cases}\boldsymbol{k}_{\mathrm{n}}^{\mathrm{p}} \boldsymbol{u}_{\mathrm{n}} & \boldsymbol{u}_{\mathrm{n}} \geq 0 \\
\mathbf{0} & \boldsymbol{u}_{\mathrm{n}}<0\end{cases} \\
\boldsymbol{F}_{\mathrm{s}}^{\mathrm{p}}= \begin{cases}\left(\boldsymbol{F}_{\mathrm{s}}^{\mathrm{p}}\right)_{0}-k_{\mathrm{s}}^{\mathrm{p}} \Delta \boldsymbol{u}_{\mathrm{s}} & \boldsymbol{F}_{\mathrm{s}}^{\mathrm{p}} \leq \boldsymbol{F}_{\mathrm{s}}^{\max } \\
\boldsymbol{F}_{\mathrm{s}}^{\max }=\mu \boldsymbol{F}_{\mathrm{n}}^{\mathrm{p}} & \boldsymbol{F}_{\mathrm{s}}^{\mathrm{p}}>\boldsymbol{F}_{\mathrm{s}}^{\max }\end{cases} \\
\boldsymbol{M}_{\mathrm{r}}^{\mathrm{p}}= \begin{cases}k_{\mathrm{r}}^{\mathrm{p}} \Delta \boldsymbol{\theta}_{\mathrm{r}} & \boldsymbol{M}_{\mathrm{r}}^{\mathrm{p}} \leq \boldsymbol{M}_{\mathrm{r}}^{\max } \\
\boldsymbol{M}_{\mathrm{r}}^{\max }=0.25 \zeta_{\mathrm{c}} \boldsymbol{F}_{\mathrm{n}}^{\mathrm{p}} \bar{R} & \boldsymbol{M}_{\mathrm{r}}^{\mathrm{p}}>\boldsymbol{M}_{\mathrm{r}}^{\max }\end{cases} \\
\boldsymbol{M}_{\mathrm{t}}^{\mathrm{p}}= \begin{cases}k_{\mathrm{t}}^{\mathrm{p}} \Delta \boldsymbol{\theta}_{\boldsymbol{t}} & \boldsymbol{M}_{\mathrm{t}}^{\mathrm{p}} \leq \boldsymbol{M}_{\mathrm{t}}^{\max } \\
\boldsymbol{M}_{\mathrm{t}}^{\max }=0.65 \mu \boldsymbol{F}_{\mathrm{n}}^{\mathrm{p}} \bar{R} & \boldsymbol{M}_{\mathrm{t}}^{\mathrm{p}}>\boldsymbol{M}_{\mathrm{t}}^{\max }\end{cases}
\end{gathered}
$$

where $k_{\mathrm{n}}^{\mathrm{p}}, k_{\mathrm{s}}^{\mathrm{p}}, k_{\mathrm{r}}^{\mathrm{p}}, k_{\mathrm{t}}^{\mathrm{p}}$ are the normal, shear, bending and torsional stiffness, respectively, $\boldsymbol{u}_{\mathrm{n}}$ is the overlap, $\left(\boldsymbol{F}_{\mathrm{s}}^{\mathrm{p}}\right)_{0}$ is the tangential contact force in the previous step, $\mu$ is the inter-particle friction coefficient, $\zeta_{c}$ is the parameter accounting for the local particle breakage. $\Delta \boldsymbol{u}_{\mathrm{s}}, \Delta \boldsymbol{\theta}_{\mathrm{r}}, \Delta \boldsymbol{\theta}_{\mathrm{t}}$ are the increments of the relative tangential displacement, bending angle and torsion angle in a time step, respectively. $\bar{R}$ is the contact radius. See more details in reference [12] (Jiang et al., 2015a).

For the $\mathrm{MH}$ bond part, the mechanical response could be estimated as follows:

$$
\begin{aligned}
\boldsymbol{F}_{\mathrm{n}}^{\mathrm{b}} & \leftarrow \boldsymbol{F}_{\mathrm{n}}^{\mathrm{b}}+k_{\mathrm{n}}^{\mathrm{b}} \Delta \boldsymbol{u}_{\mathrm{n}}^{\mathrm{b}} \\
\boldsymbol{F}_{\mathrm{s}}^{\mathrm{b}} & \leftarrow \boldsymbol{F}_{\mathrm{s}}^{\mathrm{b}}+k_{\mathrm{s}}^{\mathrm{b}} \Delta \boldsymbol{u}_{\mathrm{s}}^{\mathrm{b}} \\
\boldsymbol{M}_{\mathrm{r}}^{\mathrm{b}} & \leftarrow \boldsymbol{M}_{\mathrm{r}}^{\mathrm{b}}+k_{\mathrm{r}}^{\mathrm{b}} \boldsymbol{\Delta} \boldsymbol{\theta}_{\mathrm{r}}^{\mathrm{b}} \\
\boldsymbol{M}_{\mathrm{t}}^{\mathrm{b}} & \leftarrow \boldsymbol{M}_{\mathrm{t}}^{\mathrm{b}}+k_{\mathrm{t}}^{\mathrm{b}} \boldsymbol{\Delta} \boldsymbol{\theta}_{\mathrm{t}}^{\mathrm{b}}
\end{aligned}
$$

where $k_{\mathrm{n}}^{\mathrm{b}}, k_{\mathrm{s}}^{\mathrm{b}}, k_{\mathrm{r}}^{\mathrm{b}}$ and $k_{\mathrm{t}}^{\mathrm{b}}$ are the normal, tangential rolling and torsional stiffness of bond material (Shen et al., 2016). $\Delta \boldsymbol{u}_{\mathrm{n}}^{\mathrm{b}}, \Delta \boldsymbol{u}_{\mathrm{s}}^{\mathrm{b}}, \quad \Delta \boldsymbol{\theta}_{\mathrm{r}}^{\mathrm{b}}$ and $\Delta \boldsymbol{\theta}_{\mathrm{t}}^{\mathrm{b}}$ are the increments of the relative normal displacement, tangential displacement, bending angle and torsion angle of bond contact, respectively.

The bond strength envelope under composite load can be described using an ellipsoid, which can be practically calculated as follows:

$$
\left(\frac{\left\|\boldsymbol{F}_{\mathrm{s}}^{\mathrm{b}}\right\|}{R_{\mathrm{s}}^{\mathrm{b}}}\right)^{2}+\left(\frac{\left\|\boldsymbol{M}_{\mathrm{r}}^{\mathrm{b}}\right\|}{R_{\mathrm{r}}^{\mathrm{b}}}\right)^{2}+\left(\frac{\left\|\boldsymbol{M}_{\mathrm{t}}^{\mathrm{b}}\right\|}{R_{\mathrm{t}}^{\mathrm{b}}}\right)^{2} \begin{cases}<1 & \text { Intact } \\ =1 & \text { Critical } \\ >1 & \text { Broken }\end{cases}
$$

where $R_{s}^{b}, R_{r}^{b}, R_{t}^{b}$ are the peak shear, bending and torsional loads, respectively. Details of these parameters can be referred in [10] (Jiang et al., 2015b).

\subsection{The effect of temperature, water pressure and salinity on mechanical behavior of MH}

1.Thermo-hydro-mechanical effects

Hyodo et al. (2002) showed that the temperature and pressure affect the MH strength significantly, which can be described by using the minimum distance $L$ between the normalized test condition point and the normalized stability boundary line.

Fig. 1 summarized the relationships between the modified hydrate strength and the parameter $L$ in previous literatures (Hyodo et al., 2015; Hyodo et al., 2002; Nabeshima and Masui, 2003; Nabeshima et al., 2005; Song et al., 2010). It shows that a linear function $q_{\max }=69.38 \times L$, can be used to describe the relationship between the hydrate strength and the parameter $L$. It is worth mentioning that the compressive strength $\sigma_{c}$ and tensile strength $\sigma_{t}$ of hydrate can be modified as follows to take the backpressure $\sigma_{w}$ into consideration:

$$
\begin{gathered}
\sigma_{\mathrm{c}}=q_{\max }=\sigma_{\mathrm{c}, \mathrm{f}}-\sigma_{\mathrm{w}}=69.38 \times L\left(\sigma_{\mathrm{w}}, \mathrm{T}\right) \\
\sigma_{\mathrm{t}}=\sigma_{\mathrm{w}}-\sigma_{\mathrm{t}, \mathrm{f}}=69.38 \times L\left(\sigma_{\mathrm{t}, \mathrm{f}}, T\right)
\end{gathered}
$$

where $\sigma_{\mathrm{cf}}$ is the major stress in compression failure and $\sigma_{\mathrm{tf}}$ is the major stress in tensile failure. 


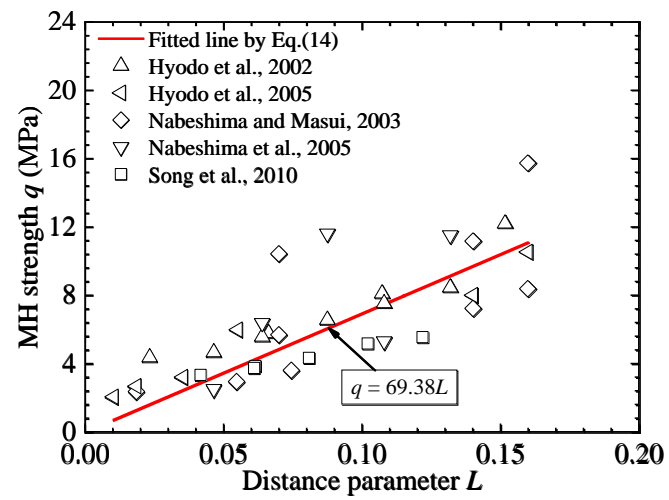

Fig. 1. Relationship between MH strength and temperature and pressure parameters.

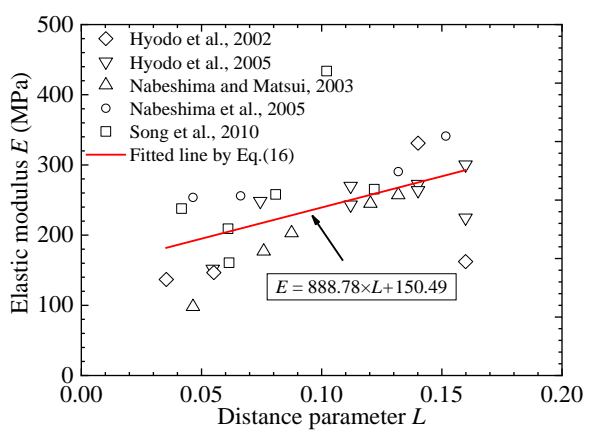

Fig. 2. Relationship between MH modulus and temperature and pressure parameters.

Fig. 2 provides the available experimental data of the elastic modulus of hydrate at different temperatures and pressures (Hyodo et al., 2015; Hyodo et al., 2002; Nabeshima and Masui, 2003; Nabeshima et al., 2005; Song et al., 2010). It shows that the elastic modulus of hydrate can be expressed as follows:

$$
E=888.78 \times L+150.49
$$

\section{Chemical effects}

Previous researches show that the chemicals such as $\mathrm{NaCl}$ can shift the $\mathrm{MH}$ phase equilibrium line and consequently changes the parameter $L$. Fig. 3 summarizes the phase equilibrium lines of hydrates in $\mathrm{NaCl}$ solutions with different concentrations in existing literatures (Maekawa, 2001; Dholabhai et al., 1991;
Jager and Sloan, 2001; Kharrat and Dalmazzone, 2003; $\mathrm{Lu}$ and Matsumoto, 2005; Lafond et al., 2012; Cha et al., 2016; Sylva et al., 2016). The data can be divided into six series: $3 w t \%$, $6 \mathrm{wt} \%, 11 \mathrm{wt} \%, 17 \mathrm{wt} \%$, 22wt $\%$ and $24 \mathrm{wt} \%$ as shown in Fig.4. The lower slope of methane hydrate on the right side of $\left(\mathrm{T}_{0}, \mathrm{P}_{0}\right)$ in $\mathrm{NaCl}$ solutions with different concentrations is assumed to be parallel to that in pure water. The phase equilibrium lines of $\mathrm{MH}$ at different salt solution can be calculated using Eq. (17):

$$
\ln \left(P / P_{0}\right)= \begin{cases}-35 \times\left(T_{0} / T\right)+a & T \leq T_{0} \\ -7.5 \times\left(T_{0} / T\right)+b & T>T_{0}\end{cases}
$$

where the parameters $a$ and $b$ are the interceptions of the temperature and pressure phase equilibrium line of $\mathrm{MH}$. Then, the effect of salinity $\omega$ can be introduced by the following equations:

$$
\begin{aligned}
& a / a_{0}=0.00059 \times\left(w / w_{0}\right)^{2}+0.00253 \times\left(w / w_{0}\right)+1 \\
& b / b_{0}=0.00059 \times\left(w / w_{0}\right)^{2}+0.00253 \times\left(w / w_{0}\right)+1
\end{aligned}
$$

where $a_{0}=35$ and $b_{0}=7.5$ are the interception of the equilibrium line of methane hydrate in pure water, respectively, and $w_{0}$ is the average salinity of seawater $\left(w_{0}=3 w t \%\right)$.

The whole area can be divided into three areas as shown in Fig. 5. BD is the angle bisector separating area I and II. Line AB is used to calculate $L$ in area I while line BC is used in area II. In area III, MH would dissociate. Thus, the test condition parameter $L$ which is temperature, pressure and chemical dependent can be calculated using Equation (20).

In the DEM simulation, the environmental parameters (temperature $T$, water pressure $P$ and salinity $\omega$ ) of the MHBS are inputted before hydrate formation. The hydrate phase equilibrium line depends on the inputted environmental salinity, and the tensile strength, compressive strength and modulus of hydrate are determined by the parameter $L$ which depends on the temperature and water pressure.

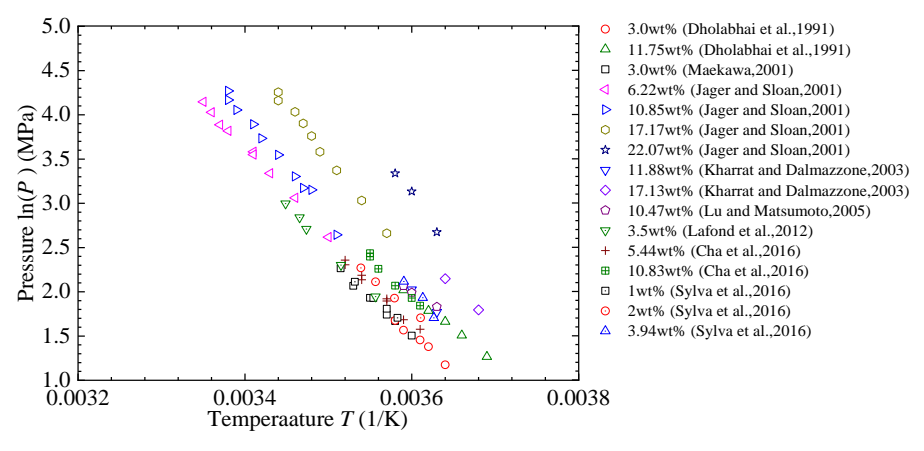

Fig. 3. Temperature-pressure boundary point of methane hydrate in different concentrations of $\mathrm{NaCl}$ solution. 


$$
L=\left\{\begin{array}{cc}
\left|35 \times\left(T_{0} / T\right)+\ln \left(P / P_{0}\right)-35 \times\left[0.00059 \times\left(w / w_{0}\right)^{2}+0.00253 \times\left(w / w_{0}\right)+1\right]\right| / \sqrt{3.5^{2}+1^{2}} & \text { Zone I } \\
7.5 \times\left(T_{0} / T\right)+\ln \left(P / P_{0}\right)-7.5 \times\left[0.00059 \times\left(w / w_{0}\right)^{2}+0.00253 \times\left(w / w_{0}\right)+1\right] \mid / \sqrt{7.5^{2}+1^{2}} & \text { Zone I } \\
0 & \text { Zone II }
\end{array}\right.
$$

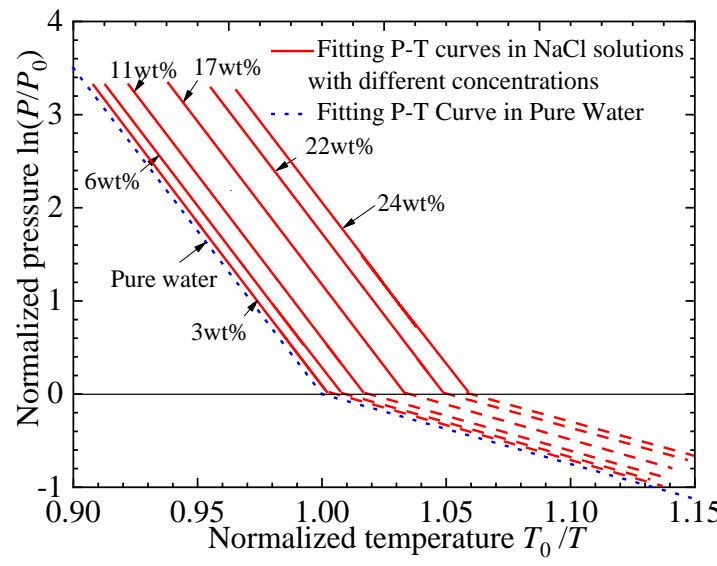

Fig. 4. Phase equilibrium of hydrate in different concentration of $\mathrm{NaCl}$ solution.

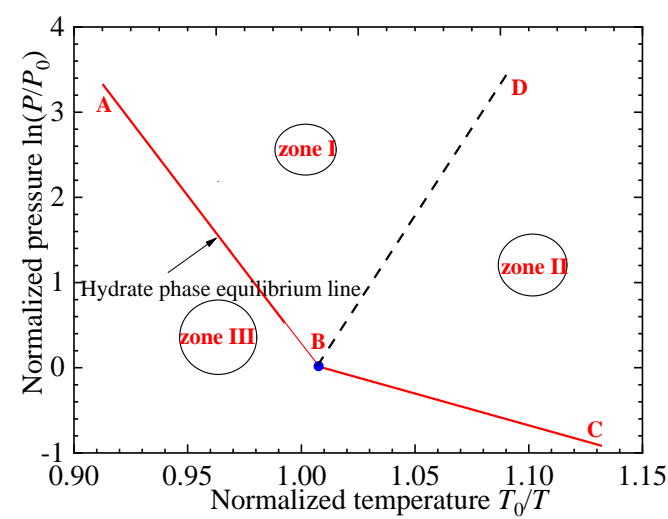

Fig. 5. Equilibrium lines of hydrate phase and temperature and pressure conditions in the test.

\section{DEM SIMULATIONS OF DISSOCIATION BY CHEMICAL INJECTION METHOD}

\subsection{Samples and initial conditions}

The DEM sample was generated with 40000 particles by the Multi-layer Under- compaction method (UCM) (Jiang et al., 2003) with a target size of $5.5 \mathrm{~mm} \times 5.5 \mathrm{~mm} \times 11 \mathrm{~mm}$. The particle parameters are provided in Table 1.

An effective confining pressure of $200 \mathrm{kPa}$ was applied isotropically until the equilibrium state was reached. Then the $\mathrm{MH}$ bond was formed with a $\mathrm{MH}$ saturation of $40 \%$ and the effective confining pressure was increased from $0.2 \mathrm{MPa}$ to $5 \mathrm{MPa}$. Hereafter the effective confining pressure was maintained at $5 \mathrm{MPa}$.

The initial temperature $T=278 \mathrm{~K}$ and back pressure $\sigma_{w}=10 \mathrm{MPa}$. And the initial salinity is $3 \mathrm{wt} \%$, which is the average salinity of the seawater.

Fig. 6 provides the relationship between the axial strain and deviator stress in the pure sand and non-dissociation MHBS. In order to simulate the actual engineering conditions, three deviator stresses were adopted: 0MPa (Point A), 8MPa (Point B) and $10 \mathrm{MPa}$ (Point $\mathrm{C}$ ) as shown in the figure. This is because $8 \mathrm{MPa}$ is smaller than the pure sand compression strength while $10 \mathrm{MPa}$ is larger than the pure sand compression strength but smaller than the MHBS compression strength.

Table 1. Parameters of MHBS contact model.

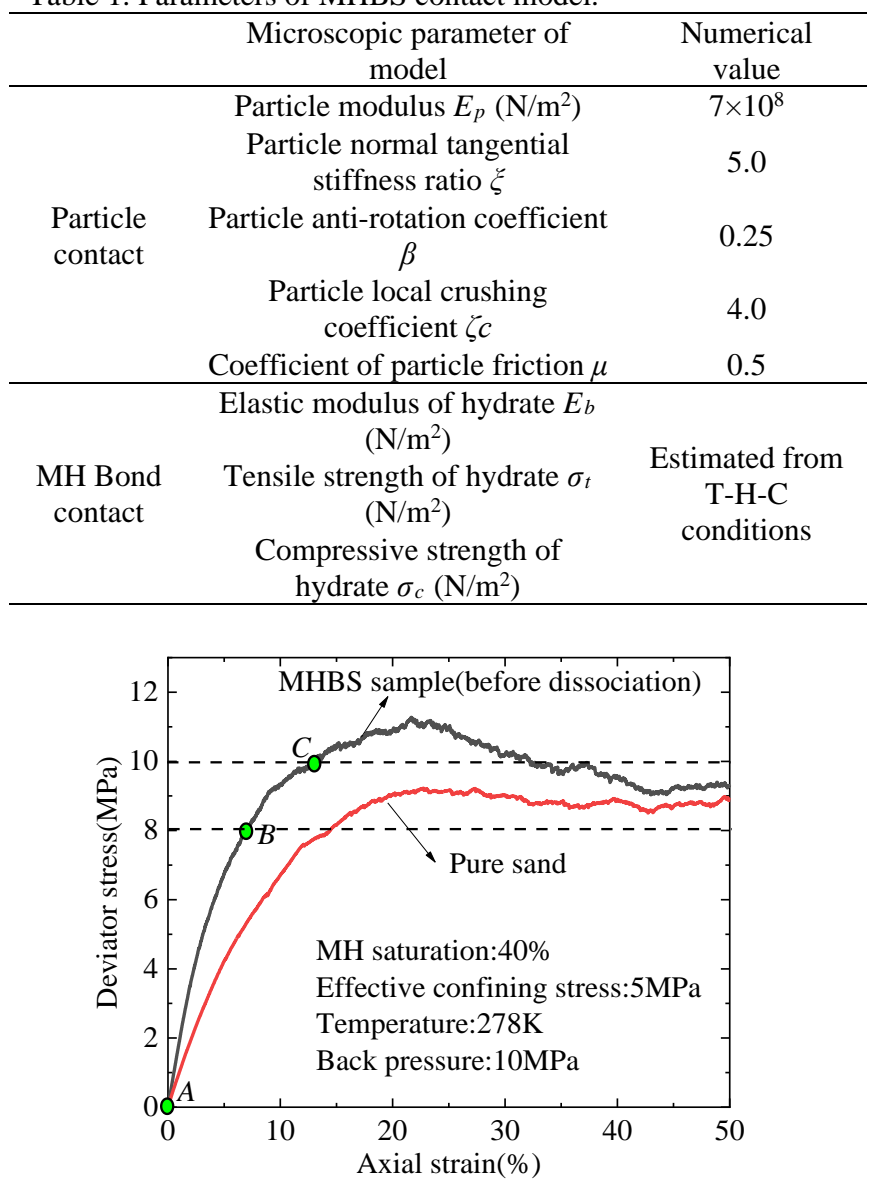

Fig. 6. Relationship between axial strain and deviator stress.

Note that the hydrate is assumed to dissociate as soon as the test condition reaches the stability boundary line in this study.

\subsection{Simulation procedure}

Fig. 7 illustrates the relationship between salinity and time in DEM simulation. It is worth mentioning that the tests conditions are kept invariant in the dissociation and recovery process, including the deviator stress, temperature (278K), effective confining pressure (5MPa) and back pressure (10MPa). 
The chemical injection process which lasts for 1000s can divided into three phases: increasing stage, stable stage and recovery stage. In the increasing stage the salinity increases with a rate of $2 \mathrm{wt} \% / \mathrm{min}$ from $3 \mathrm{wt} \%$ to nearly $14 \mathrm{wt} \%$ (nearly $330 \mathrm{~s}$ ), when the phase equilibrium line exceeds the temperature and pressure point in the test. In the stable stage the salinity remains constant for $\mathrm{MH}$ dissociation which lasts nearly 570s. In the recovery stage the salinity decreases to the initial value of $3 \mathrm{wt} \%$ instantly and remains constant for $100 \mathrm{~s}$. Note that the formation of new hydrate is excluded in the recovery stage in the study.

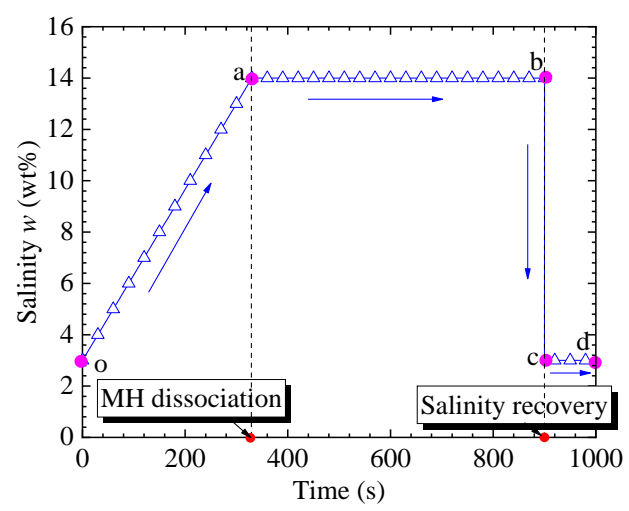

Fig. 7. Salinity versus time during chemical injection process.

\subsection{Macro-and micro scale mechanical responses of chemical injection recovery tests}

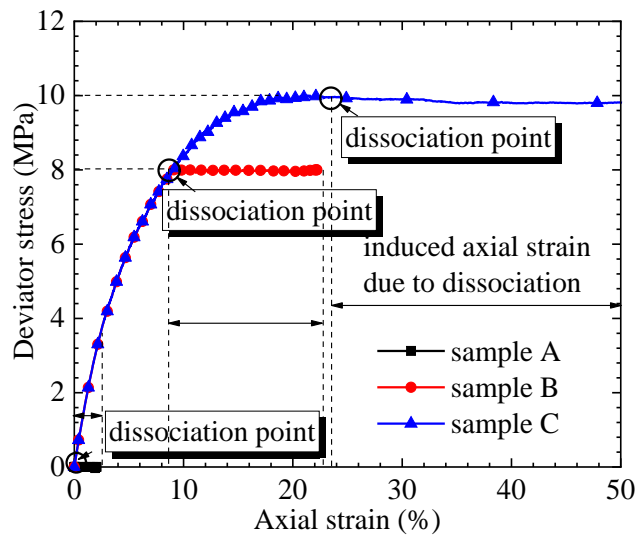

Fig. 8. Stress-strain response in DEM simulation during chemical injection process.

Fig.8 provides the evolutions of deviator stress with axial strain during the whole test in DEM simulations. Note that the dissociation point represents the time when the salinity starts to increase. When the deviator stress is $0 \mathrm{MPa}$ (Sample A), the axial strain due to chemical injection increases from $0 \%$ to $2 \%$ and then it remains constant after the $\mathrm{MH}$ dissociates completely. For Sample B in which the deviator stress is $8 \mathrm{MPa}$, the axial strain due to chemical injection increases from $9 \%$ to $21 \%$, then it remains constant after $\mathrm{MH}$ dissociation. With regard to Sample C with a deviator stress of 10
MPa, the axial strain due to chemical injection keeps increasing rapidly, which implies that the sample has collapsed without the enhancement of MH bond.

Fig.9 provides the evolutions of the void ratio with axial strain during chemical injection process. It shows that all the three samples experience volumetric contraction. For Samples A and B where the initial stress is small, the volumetric strain decreases to a certain value with the increase of the axial strain, while for Sample $\mathrm{C}$ with a larger initial stress the volumetric strain keeps decreasing because the sample has collapsed.

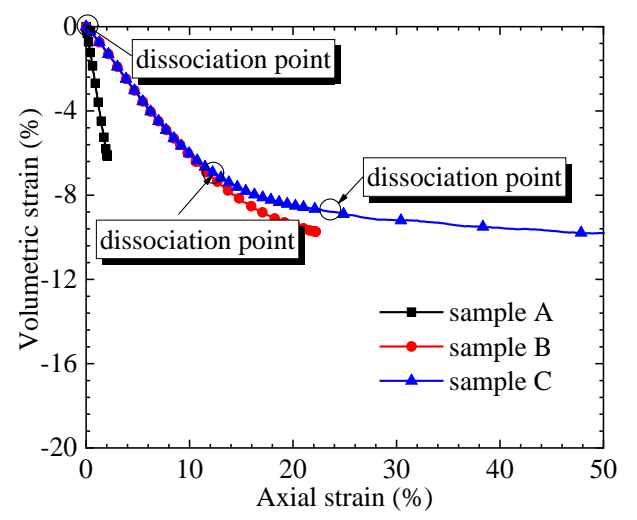

Fig. 9. Changes of void ratio with axial strain in simulation during chemical injection process.

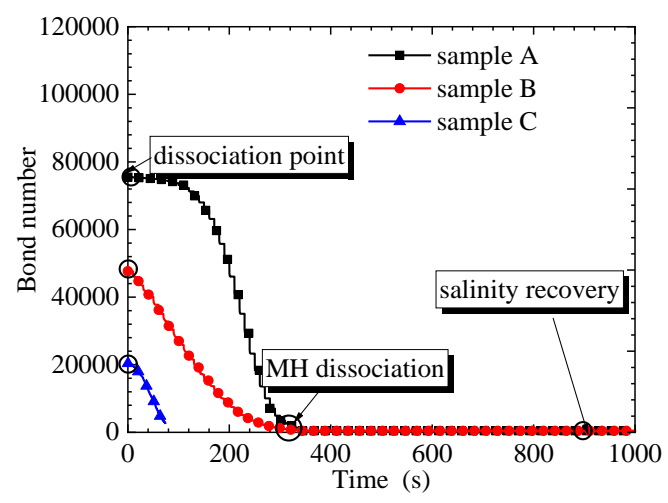

Fig. 10. Changes of bond contact number with time in simulation during chemical injection process.

The MH bond also affect the MHBS deformation in addition to the effective stress. With the salinity increases, the cage type skeleton of $\mathrm{MH}$ becomes unstable, which in turn causes the decreases of $\mathrm{MH}$ bond strength and stiffness. Fig.10 presents the evolutions of bond contact number with time in DEM simulations during chemical injection process. It shows that the bond contact number gradually decreases to zero with the increase of time in the increasing stage (i.e., the salinity increases in the increasing stage). Since no new hydrate bond forms in the recovery stage, the number of MHBS hydrate bond remains zero. 


\section{CONCLUSIONS}

A new thermo-hydro-mechanical-chemical contact model was proposed and then implemented into PFC3D to simulate the MHBS exploitation and recovery by chemical injection method. The macro and micro-scale responses were analyzed. The main conclusions can be summarized as follows:

(1) During $\mathrm{MH}$ exploitation, the axial strain increases with the increase of salinity.

(2) MHBS sample will collapse after exploitation when the deviator stress applied is larger than the compression strength of pure sand.

(3) Salinity recovery shows slight influence on the deformation of MHBS.

(4) The bond contact number decreases with the increase of time. When MH fully dissociated, the bond contact number becomes zero, and keep zero during the salinity recovery.

\section{ACKNOWLEDGEMENTS}

The research is funded by National Nature Science Foundation of China with Grant Nos.51639008, 51890911, which are sincerely appreciated.

\section{REFERENCES}

1) Cha, M., Hu, Y., and Sum, A. K. (2016): Methane hydrate phase equilibria for systems containing $\mathrm{NaCl}, \mathrm{KCl}$, and $\mathrm{NH}_{4} \mathrm{Cl}$. Fluid Phase Equilibria, 413, 2-9.

2) Cundall, P., and Strack, O. (1979): A discrete numerical model for granular assemblies. Géotechnique, 29(1), 47-65.

3) Dholabhai, P., Englezos, P., Kalogerakis, N., and Bishnoi, P. (1991): Equilibrium conditions for methane hydrate formation in aqueous mixed electrolyte solutions. The Canadian Journal of Chemical Engineering, 69(3): 800-805.

4) Englezos, P., Kalogerakis, N., and Raj Bishnoi, P. (1993): A systematic approach for the efficient estimation of interaction parameters in equations of state using binary VLE data. The Canadian Journal of Chemical Engineering,71(2), 322-326.

5) Hyodo, M., Hyde. A., Nakata, Y., Yoshimoto, N., Fukunaga, M., Kubo, K., Nanjo, Y., and Matsuo, T. (2002): Triaxial compressive strength of methane hydrate. Proceedings of the Twelfth International Offshore and Polar Engineering Conference, Kitakyushu, Japan, May 26-31, 422-428.

6) Hyodo, M., Nakata, Y., Yoshimoto, N., and Ebinuma, T. (2005): Basic research on the mechanical behavior of methane hydrate-sediments mixture. Soils and Foundations, 45(1): 75-85.

7) Hyodo, M., Yoneda, J., Yoshimoto, N., and Nakata, Y. (2013): Mechanical and dissociation properties of methane hydrate-bearing sand in deep seabed. Soils and Foundations, 53(2), 299-314.

8) Jager, M., and Sloan, E. (2001): The effect of pressure on methane hydration in pure water and sodium chloride solutions. Fluid Phase Equilibria, 185(1):89-99.

9) Jiang, M., Fu, C., Cui, L., Shen, Z., and Zhu, F. (2016): DEM simulations of methane hydrate exploitation by thermal recovery and depressurization methods. Computers and Geotechnics, 80, 410-426.

10) Jiang, M., Jin, S., Shen, Z., Liu, W., and Coop, M. (2015b): Preliminary experimental study on three-dimensional contact behavior of bonded granules. In IOP Conference Series:
Earth and Environmental Science (Vol. 26, No. 1, p. 012007). IOP Publishing.

11) Jiang, M., Konrad, J., and Leroueil, S. (2003): An efficient technique for generating homogeneous specimens for DEM studies. Computers and Geotechnics, 30, 579-597.

12) Jiang, M., Shen, Z., and Wang, J. (2015a): A novel three-dimensional contact model for granulates incorporating rolling and twisting resistances. Computers and Geotechnics, 65, 147-163.

13) Kharrat, M., and Dalmazzone, D. (2003): Experimental determination of stability conditions of methane hydrate in aqueous calcium chloride solutions using high pressure differential scanning calorimetry. The Journal of Chemical Thermodynamics, 35(9), 1489-1505.

14) Kvenvolden, K. (1988).: Methane hydrate-a major reservoir of carbon in the shallow geosphere?. Chemical Geology, 71(1-3), 41-51.

15) Lafond, P., Olcott, K., Sloan, E., Koh, C., and Sum, A. (2012), Measurements of methane hydrate equilibrium in systems inhibited with $\mathrm{NaCl}$ and methanol. Journal of Chemical Thermodynamics, 48: 1-6.

16) Lu, H., and Matsumoto, R. (2005): Experimental studies on the possible influences of composition changes of pore water on the stability conditions of methane hydrate in marine sediments. Marine Chemistry, 93(2-4), 149-157.

17) Maekawa, T. (2001): Equilibrium conditions for gas hydrates of methane and ethane mixtures in pure water and sodium chloride solution. Geochemical Journal, 35(1): 59-66.

18) Masui, A., Haneda, H., Ogata, Y., and Aoki, K. (2005, January): Effects of methane hydrate formation on shear strength of synthetic methane hydrate sediments. In The Fifteenth International Offshore and Polar Engineering Conference. International Society of Offshore and Polar Engineers. Seoul, Korea, 19-24.

19) Moridis, G., Collett, T., Dallimore, S., Satoh, T., Hancock, S., and Weatherill, B. (2004): Numerical studies of gas production from several $\mathrm{CH}_{4}$ hydrate zones at the Mallik site, Mackenzie Delta, Canada. Journal of Petroleum Science and Engineering, 43(3-4), 219-238.

20) Nabeshima, Y., and Matsui, T. (2003): Static Shear Behaviors of Methane Hydrate and Ice. The Proceedings of the Fifth ISOPE Ocean Mining Symposium. International Society of Offshore and Polar Engineers., 156-158.

21) Nabeshima, Y., Takai, Y., and Komai, T. (2005): Compressive Strength and Density of Methane Hydrate. Proceedings of the Sixth ISOPE Ocean Mining Symposium, Changsha, Hunan, China, 197-200.

22) Shen, Z., Jiang, M., and Thornton, C. (2016): DEM simulation of bonded granular material. Part I: contact model and application to cemented sand. Computers and Geotechnics, 75:192-209.

23) Shen, Z., and Jiang, M. (2016): DEM simulation of bonded granular material. Part II: extension to grain-coating type methane hydrate bearing sand. Computers and Geotechnics, 75, 225-243.

24) Song, Y., Yu, F., Li, Y., Liu, W., and Zhao, J. (2010): Mechanical property of artificial methane hydrate under triaxial compression. Journal of Natural Gas Chemistry, 19(3): 246-250.

25) Sylva, T., Kinoshita, C., and Masutani, S. (2016): Inhibiting effects of transition metal salts on methane hydrate stability. Chemical Engineering Science, 155, 10-15.

26) Yu, F., Song, Y., Li, Y., Liu, W., and Lam, W. (2011): Analysis of stress-strain behavior and constitutive relation of methane hydrate-bearing sediments with various porosity. International Journal of Offshore and Polar Engineering, 21(04), 316-322. 